Cite this: Phys. Chem. Chem. Phys., 2013, 15, 19284

Received 22nd May 2013, Accepted 12th September 2013 DOI: $10.1039 / c 3 c p 52149 d$

www.rsc.org/pccp

\title{
Guanine binding to gold nanoparticles through nonbonding interactions $\dagger$
}

\author{
Xi Zhang, ${ }^{a}$ Chang Q. Sun ${ }^{b}$ and Hajime Hirao*a
}

\begin{abstract}
Gold nanoparticles have been widely used as nanocarriers in gene delivery. However, the binding mechanism between gold nanoparticles and DNA bases remains a puzzle. We performed density functional theory calculations with and without dispersion correction on $\operatorname{Au}_{N}(N=13,55$, or 147) nanoparticles in high-symmetry cuboctahedral structures to understand the mechanism of their binding with guanine at the under-coordinated sites. Our study verified that: (i) negative charges transfer from the inner area to the surface of a nanoparticle as a result of the surface quantum trapping effect; and (ii) the valence states shift up toward the Fermi level, and thereby participate more actively in the binding to guanine. These effects are more prominent in a smaller nanoparticle, which has a larger surface-to-volume ratio. Additional fragment orbital analysis revealed that: (i) electron donation from the lone-pair orbital of $N$ to the unoccupied orbital of the Au cluster occurs in all complexes; (ii) $\pi$ backdonation occurs from the polarized $A u d_{y z}$ orbital to the $N p_{y}-\pi^{*}$ orbital when there is no $A u \cdots H-N$ hydrogen bond, and, (iii) depending on the configuration, $\mathrm{Au} \cdots \mathrm{H}-\mathrm{N}$ hydrogen bonding can also exist, to which the Au occupied orbital and the $\mathrm{H}-\mathrm{N}$ unoccupied orbital contribute.
\end{abstract}

\section{Introduction}

Gold nanoparticles (NPs) are size-tunable materials that function as efficient nanocarriers in the delivery of peptides, proteins, DNA, or RNA. ${ }^{1,2}$ The reported noncytotoxicity ${ }^{3}$ and high efficiency of gold $\mathrm{NPs}^{2,4}$ reinforce the expectation that gold NPs should serve as appropriate vehicles for gene delivery. It is well known that gold in bulk is so inert that it has only a low adsorption capacity. Then why and how do gold NPs acquire adsorption ability? Answering this question is of crucial importance for the effective application of gold NPs in gene delivery. In particular, it is necessary to understand the roles of under-coordinated atoms at gold surfaces, the effects of $\mathrm{Au} d$ electrons on the interaction with biomolecules such as DNA, and the binding patterns in such interactions.

A large proportion of atoms of a gold NP at the surface, edge, defects, or other kinds of boundaries of nanostructures are under-coordinated. In fact, the volume ratio of the surface layer to the entire body, referred to as the surface-to-volume ratio, increases with decreasing size of a NP. The ratio can be $90 \%$ for

\footnotetext{
${ }^{a}$ Division of Chemistry and Biological Chemistry, School of Physical and Mathematical Sciences, Nanyang Technological University, 21 Nanyang Link, Singapore 637371.E-mail: hirao@ntu.edu.sg

${ }^{b}$ School of Electric and Electronic Engineering, Nanyang Technological University, 50 Nanyang Avenue, Singapore 639794

† Electronic supplementary information (ESI) available. See DOI: 10.1039/ c3cp52149d
}

a gold NP with a diameter of $1 \mathrm{~nm}$. A large surface-to-volume ratio has been shown to give rise to the "under-coordination effect" of gold NPs, ${ }^{5,6}$ which has recently been drawing rapidly increasing attention. ${ }^{7,8}$ The under-coordination effect exerts considerable influences on the structure, bonding, energy, and behavior of gold NPs. ${ }^{5,9}$ For example, Au-Au bonds are shortened around the under-coordinated sites, ${ }^{5,10,11}$ and surface potential energy is elevated in gold NPs. ${ }^{12}$ Moreover, the energy states and electronic structures of gold NPs differ significantly from those of bulk gold, ${ }^{13,14}$ which can also be attributed to the under-coordination effect. These under-coordination-induced properties provide tunability in electron conductivity, ${ }^{15}$ local magnetism, ${ }^{16}$ and catalytic ability ${ }^{7,8,17}$ of gold atoms in a nanoisland on substrates, stepped surfaces, nanoporous materials, ${ }^{7}$ nanoparticles, etc.

In gene delivery, gold-molecule (or -base) interactions, which are ubiquitous in science, ${ }^{18,19}$ may be effectively exploited. At the molecular level, such interactions involve a bond between $\mathrm{Au}$ and, e.g., $\mathrm{N}$ of an organic molecule. This bond may not be described as a pure $\mathrm{N}-\mathrm{Au}$ donor-acceptor bond, ${ }^{19}$ because back-donation of gold $5 \mathrm{~d}$ electrons to an organic molecule may also exist. ${ }^{18,20,21}$

Unconventional $\mathrm{N}-\mathrm{H} \cdots \mathrm{Au}$ hydrogen bonding is another interesting structural feature of gold-molecule complexes. ${ }^{22-26}$ On the basis of computational studies, unconventional hydrogen bonds have been claimed to exist in the complexes of gold with pterin, ${ }^{22}$ glycine, ${ }^{23}$ and ammonia, ${ }^{26}$ whereas such 
hydrogen bonding was not observed in the complex of gold and $\mathrm{PH}_{3}{ }^{24}$

Precise characterization of these key structural and electronic factors controlling the properties and interactions of gold NPs should help establish the molecular basis for the effective application of gold NPs in gene delivery. Density functional theory (DFT) has useful roles to play in this endeavor. So far, a few DFT studies have been performed on relatively small and low-symmetry DNA base-gold [ $\left.\mathrm{Au}_{N}(N=2-20)\right]$ complexes. ${ }^{27-32}$ Kryachko and Remacle investigated the complexes between $\mathrm{Au}_{N}$ $(N=2-6)$ and nucleobases or base pairs. ${ }^{31}$ Kumar et al. studied the complexes between the adenine-thymine (AT) or the guaninecytosine (GC) pair and $\mathrm{Au}_{N}(N=4,8) .{ }^{27}$ Shukla et al. ${ }^{30}$ studied the interaction between gold nanoclusters $\operatorname{Au}_{N}(N=2,4,6,8,10,12)$ and the purine base in guanine $(\mathrm{G})$ and the $\mathrm{GC}$ base pair. Martínez ${ }^{29}$ analyzed the properties of planar and 3-D gold clusters $\left(\mathrm{Au}_{N}\right.$ with $\left.N=2-20\right)$ interacting with the adenine-uracil (AU) and GC base pairs. ${ }^{32}$ Zhang et al. investigated the interaction of $\mathrm{G}$ base with $\mathrm{Au}_{N}(N=2,4,6,8) \cdot{ }^{33,34}$ Despite extensive DFT studies, however, the core size of the experimentally synthesized particles usually falls in the range between $1.5 \mathrm{~nm}$ $\left(\sim \mathrm{Au}_{55}\right)$ and $\sim 6 \mathrm{~nm},{ }^{35,36}$ and clusters tend to adopt a highsymmetry structure (i.e., truncated octahedral, cuboctahedral, icosahedral or decahedral nanocrystal), as corroborated by studies based on the Wulff construction, ${ }^{37}$ genetic algorithms, ${ }^{38,39}$ and first-principles methods, ${ }^{40}$ as well as by experiments. ${ }^{41-43}$ Clearly, computational studies should be performed on the interactions between larger gold NPs and bases.

In this work, complexes between high-symmetry cuboctahedral NPs with relatively large sizes $\left(\mathrm{Au}_{13}, \mathrm{Au}_{55}\right.$ and $\left.\mathrm{Au}_{147}\right)$ and the guanine $(\mathrm{G})$ nucleobase are studied using DFT. The main goal of this work is to identify the mechanism underlying the binding between $\mathrm{G}$ and gold NPs from the perspective of undercoordination effects ${ }^{6}$ on charge redistribution, local structure relaxation, and electronic properties of gold NPs. ${ }^{9,10}$ We chose $\mathrm{G}$ because it is a well-studied DNA base $\mathrm{e}^{30,33,34}$ that therefore allows us to investigate the role of under-coordinated gold in adsorption processes using the reported stable binding patterns. ${ }^{30,31}$ Moreover, to better characterize the donor-acceptor and H-bonding interactions between the gold NPs and G, we perform fragment orbital analyses of $\mathrm{Au}_{13}-\mathrm{G}$ and atomic-orbital bond-order analyses of all complexes.

\section{Methods}

\subsection{Structures and principles}

Gold NPs in cuboctahedral structures of three "magic sizes", 44 i.e., $\mathrm{Au}_{13}$ ( 2 atomic shells), $\mathrm{Au}_{55}$ (3 atomic shells), and $\mathrm{Au}_{147}$ (4 atomic shells) were considered in this study. The cuboctahedral structure has been proven stable in gold clusters with relatively large sizes that consist of $>50$ atoms. ${ }^{38,39}$ The icosahedral structure is also stable in $\mathrm{Au}_{13}{ }^{40}$ We also examined icosahedral $\mathrm{Au}_{13}$; however, the binding energy (BE) for icosahedral $\mathrm{Au}_{13}-\mathrm{G}$ was much smaller $\left(28.5 \mathrm{kcal} \mathrm{mol}^{-1}\right)$ than that for cuboctahedral $\mathrm{Au}_{13}-\mathrm{G}$ (44.9 $\mathrm{kcal} \mathrm{mol}^{-1}$ ). Therefore, we focused mainly on cuboctahedral NPs in studying the size-dependent under-coordination effects and unconventional hydrogen bonding.

Fig. 1 illustrates the $\mathrm{Au}-\mathrm{N}$ bonding sites for the interaction between guanine (N2 or N5) and $\mathrm{Au}_{13}$ NPs. Two configurations were chosen from the most stable binding sites of $\mathrm{Au}-\mathrm{G}$ complexes. $^{31}$ Consistent with the reported ${ }^{45}$ and our previous results, ${ }^{9}$ the corner atom of $\mathrm{Au}_{55}$ forms a stronger bond with guanine (BE: $35.3 \mathrm{kcal} \mathrm{mol}^{-1}$ ) than the edge atoms (BE: $24.2 \mathrm{kcal} \mathrm{mol}^{-1}$ ). Therefore, in the following discussions, we shall focus on the interactions at the most under-coordinated corner atoms. The cross sections of $\mathrm{Au}_{55}$ and $\mathrm{Au}_{147}$ are shown in the figure of Mulliken charges (Fig. 2).

Fig. 1c illustrates the under-coordination-induced bond contraction, surface quantum trapping, and charge polarization of gold NPs, as reported in the theme articles. ${ }^{46,47}$ Our recent study ${ }^{9}$ demonstrated that the length of the $\mathrm{Au}-\mathrm{Au}$ interlayer bond contracts from the bulk value of $2.883 \AA$ to
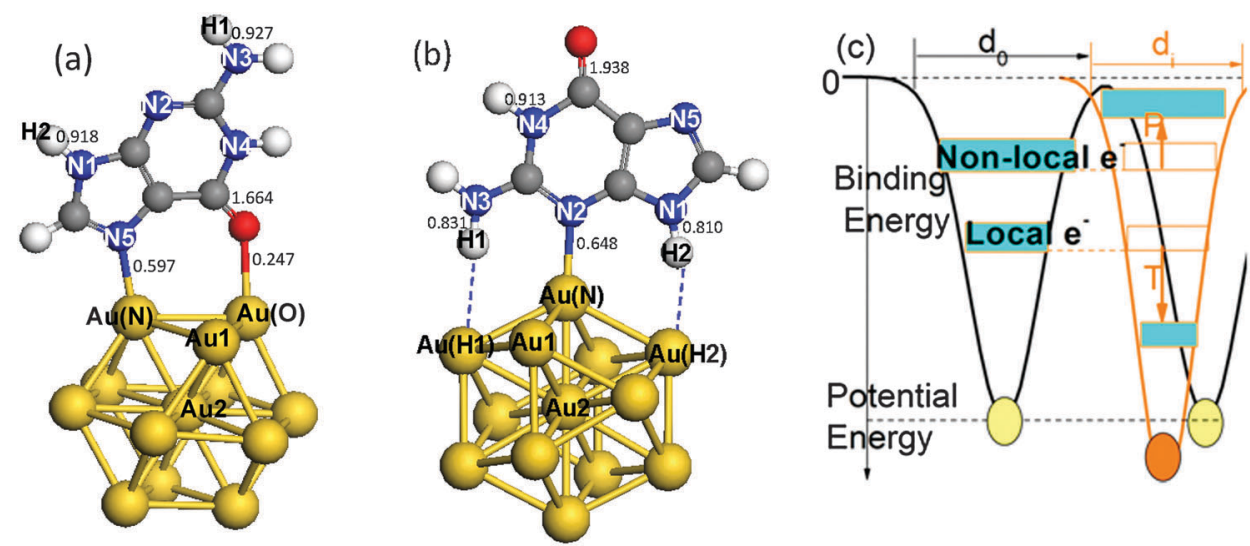

Fig. 1 Illustration of the structures and under-coordination effects. Gold atom-shell labels extend from the surface corner toward the center, Au1 and Au2. N atoms in guanine are labeled $\mathrm{N} 1-\mathrm{N} 5$. Two $\mathrm{H}$ atoms on $\mathrm{N} 3$ and $\mathrm{N} 1$ are labeled $\mathrm{H} 1$ and $\mathrm{H} 2$. (a) The $\mathrm{Au}_{13}-\mathrm{G} 1$ complex with the gold binding sites labeled $\mathrm{Au}(\mathrm{N})$ and $\mathrm{Au}(\mathrm{O})$. The binding pattern involves $\mathrm{Au}(\mathrm{N})-\mathrm{N} 5$ and $\mathrm{Au}(\mathrm{O})-\mathrm{O}$ bonds. (b) The $\mathrm{Au}_{13}-\mathrm{G} 2$ complex with the gold binding sites labeled $\mathrm{Au}(\mathrm{N}), \mathrm{Au}(\mathrm{H} 1)$ and $\mathrm{Au}(\mathrm{H} 2)$. This binding pattern involves a $\mathrm{Au}(\mathrm{N})-\mathrm{N} 2$ bond and two N-H...Au hydrogen bonds. (c) Illustration of under-coordination-induced bond contraction, surface quantum trapping (T), and valence charge polarization (P) at the surface. Values in (a) and (b) are the calculated Mayer bond orders for the $\mathrm{Au}_{13}-\mathrm{G}$ complexes. ${ }^{48}$ 


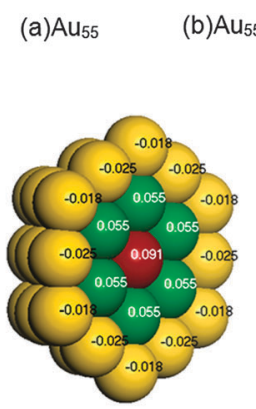

(b) $\mathrm{Au}_{55}-\mathrm{G} 1$

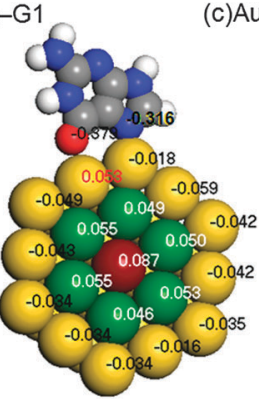

(d) $\mathrm{Au}_{147}$

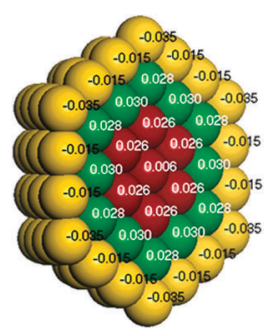

(e)Aur

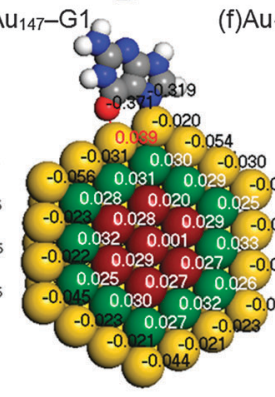

(c) $\mathrm{Au}_{55}-\mathrm{G} 2$

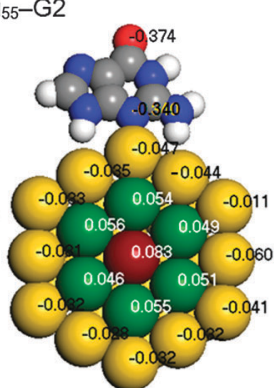

Fig. 2 Core-shell separations of Mulliken charges in cross sections of (a) $A u_{55}$ (b) $A u_{55}-G 1$, (c) $A u_{55}-G 2$, (d) $A u_{147}$, (e) $A u_{147}-G 1$, and (f) $A u_{147}-G 2$. A negative value (black) means electronic gain and a positive value (white and red) means electronic loss.

2.694 $\AA$ in the outermost two shells of Au NPs. The effective coordination number $z$ is shell-dependent, ${ }^{9,10}$ i.e.

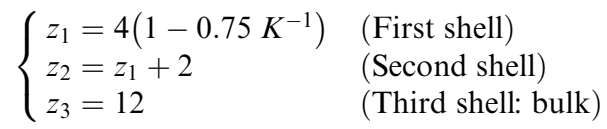

where $K$ is the size factor calculated from the particle diameter over the atomic radius. A radial dependence of bond contraction was observed, and the effect was prominent in the two outermost layers of gold nanoparticles. ${ }^{10,11}$ The principle of least energy states that a spontaneous process is associated with an internal energy decrease. Therefore, bond contraction is accompanied by single-bond energy gain and depression of the interatomic potential well. ${ }^{12}$ Because of the potential well entrapment and core-level blue shift, ${ }^{6}$ valence charges tend to 'flow' from the inner part of the bulk to the surface skin. This is referred to as the quantum trapping effect. The valence charges will be locally polarized by the densely entrapped core electrons at the surface and occupy the higher-energy states near the Fermi level $\left(E_{\mathrm{F}}\right)$ to form a polarization state. The polarization states of a gold chain end, islands and nanoparticles have been observed by scanning tunneling spectroscopy. ${ }^{13,14}$

\subsection{Calculation procedures}

Spin-unrestricted DFT calculations were performed using the $\mathrm{DMol}^{3}$ code with the double numeric atomic orbital plus polarization basis set. ${ }^{49}$ A DFT semi-core pseudopotential ${ }^{50}$ was used to describe the inner electrons while including some degrees of relativistic effects. The Perdew-Wang (PW92) functional ${ }^{51}$ in the localized density approximation (LDA), the Perdew-BurkeErnzerhof (PBE) functional ${ }^{52}$ in the generalized gradient approximation (GGA), and the PBE functional with a dispersion correction based on the Tkatchenko-Scheffler scheme (DC-PBE) ${ }^{53}$ were used for calculation of the BE. The use of hybrid functionals for the systems considered in this study is prohibitive because of the high demand of the Hartree-Fock exchange energy calculation. Besides, for the studies of high-symmetry noble metal nanoparticles, LDA $^{54,55}$ and GGA functionals ${ }^{24,45,56,57}$ have been extensively used. Because the trend in the calculated $\mathrm{BE}$ was not altered in a functional-dependent manner, only the PW92 functional was used for calculations of other properties. The threshold for self-consistent field (SCF) iterations was set at $10^{-6}$ (Hartree). To overcome the energy fluctuation that is caused by the existence of many energy states near $E_{\mathrm{F}}$ in large gold NPs $\left(\geq \sim \mathrm{Au}_{55}\right)$, thermal smearing of 0.005 Hartree was applied in the initial optimizations to allow electrons to be smeared out over several orbitals using the finite-temperature Fermi function. ${ }^{58}$ The smearing was suppressed in the final optimization to obtain integer orbital occupations. No symmetry was imposed on the geometry during geometry optimizations. In the geometry optimization, the convergence tolerances for energy, force, and displacement were set at $10^{-5}$ Hartree, 0.002 Hartree per $\AA$, and $0.005 \AA$, respectively. COSMO $^{59}$ solvent calculations with the DC-PBE functional were also performed using the dielectric constant of water, i.e., 78.54.

In addition to the size effect of gold on the binding to $\mathrm{G}$, the BEs of two different complexes that use $\mathrm{N} 5$ and $\mathrm{N} 2$ as binding sites of $\mathrm{G}$, denoted as $\mathrm{Au}_{N}-\mathrm{G} 1$ and $\mathrm{Au}_{N}-\mathrm{G} 2$, respectively (see Fig. 1), were compared. To gain insight into the nature of the $\mathrm{Au}-\mathrm{G}$ bonding, additional fragment orbital analysis was performed for the $\mathrm{Au}_{13}$ cluster using Matlab. ${ }^{60}$ In this analysis, Kohn-Sham molecular orbitals for the complexes (MOs) and fragments (FOs) were obtained by performing non-smeared single-point calculations on the above-obtained optimized geometries of complexes. We expanded the MOs $\left(\psi_{i}^{\sigma}\right)$, or eigenvectors, in the $\mathrm{Au}_{N}-\mathrm{G}$ complex in terms of the FOs of isolated $\mathrm{Au}_{N}$ and $\mathrm{G}$ fragments, instead of using the atomic orbitals for expansion; that is, ${ }^{61}$

$$
\psi_{i}^{\sigma}=\sum_{j 1}^{\text {occ }} c_{j 1}^{\sigma} a_{j 1}^{\sigma}+\sum_{j 2}^{\text {unocc }} c_{j 2}^{\sigma} a_{j 2}^{\sigma}+\sum_{k 1}^{\text {occ }} c_{k 1} g_{k 1}+\sum_{k 2}^{\text {unocc }} c_{k 2} g_{k 2}
$$

where $\sigma(+$ or -$)$ represents spin-up or spin-down. $\psi_{i}^{+}$and $\psi_{i}^{-}$ are the $i$ th spin-up and spin-down MOs of a complex, respectively. $a_{j 1}{ }^{+}\left(a_{j 1}{ }^{-}\right)$and ${a_{j 2}}^{+}\left(a_{j 2}{ }^{-}\right)$are the $j 1$ th occupied and the $j 2$ th unoccupied FOs of $\mathrm{Au}_{N}$, and $g_{k 1}$ and $g_{k 2}$ are the $k 1$ th occupied and $k 2$ th unoccupied FOs of G, respectively. $c_{j 1}{ }^{+}$, $c_{j 2}{ }^{+}$, etc. are the corresponding expansion coefficients. It should be noted that the spin symbol is omitted for the FOs of G, because of its closed-shell character. If the coefficient of the $\mu$ th FO in the $i$ th MO is $c_{\mu i}$, population matrix elements can be calculated as

$$
P_{\mu \nu}^{\sigma}=1 \cdot S_{\mu v} \cdot \sum_{i}^{\mathrm{occ}} c_{\mu i}^{\sigma} c_{v i}^{\sigma}
$$

where $S_{\mu \nu}$ is the overlap matrix element between two FO bases $\mu$ and $\nu$. The sum of all terms of $P_{\mu \nu}$ over $\nu$ is the gross electronic 
population of the $\mu$ th FO. Here, only the $i$ th occupied MOs can be considered to have an occupation number of 1 for each spin. This orbital analysis provides FO population changes and FO expansion coefficients, which allow us to assess how electrons have shifted between the two fragments. The doublet $\mathrm{Au}_{13}-\mathrm{G}$ complex has 426 MOs for each spin, of which 163 and 162 FOs are occupied for spin-up and spin-down electrons, respectively. In the orbital analysis, the structure of $\mathrm{Au}_{13}-\mathrm{G} 1$ was reoriented in such a way that $\mathrm{Au}(\mathrm{N})$ was at the origin, the $\mathrm{Au}-\mathrm{N}$ bond aligned with the $z$ axis, and $\mathrm{Au}(\mathrm{N})$ and the $\mathrm{N} 5$ and $\mathrm{O}$ atoms of $\mathrm{G}$ defined the $x z$ plane. Similar reorientation of the structure of $\mathrm{Au}_{13}-\mathrm{G} 2$ was performed so that $\mathrm{Au}(\mathrm{N}), \mathrm{N} 2$, and $\mathrm{H} 1$ defined the $x z$ plane.

\section{Results and discussion}

\subsection{Size effect: under-coordination induced charge polarization}

3.1.1 Size-dependent binding energy. Table 1 summarizes the Au-size dependencies of the BEs of $\mathrm{Au}_{N}-\mathrm{G} 1$ and $\mathrm{Au}_{N}-\mathrm{G} 2$. The BE was defined as

$$
\mathrm{BE}=E(\mathrm{Au} \mathrm{NP})+E(\mathrm{G})-E(\text { Complex })
$$

where a large $\mathrm{BE}$ value reflects a stronger interaction between the $\mathrm{Au}_{N}$ and guanine fragments. The $\mathrm{BE}$ data obtained with the LDAPW92, GGA-PBE, and DC-PBE functionals are summarized in Table 1. Despite the different magnitudes of $\mathrm{BE}$ obtained for different functionals, consistent trends were observed. The BE increases as the cluster size decreases from $\mathrm{Au}_{147}$ to $\mathrm{Au}_{13}$; thus, the smallest $\mathrm{Au}_{13}$ can form the most strongly bound complex with $\mathrm{G}$. The stability of the complexes depends on the activity of valence charges in gold NPs. $\mathrm{Au}_{13}$ and $\mathrm{Au}_{55}$ have a larger binding energy in the second configuration $(\mathrm{Au}-\mathrm{N} 2$ and $\mathrm{Au} \cdots \mathrm{H})$ than in the first configuration (Au-N5 and $\mathrm{Au}-\mathrm{O}$ ). However, $\mathrm{Au}_{147}$ prefers the first configuration over the second configuration. Interestingly, the solvent effect provides a larger stabilization to $\mathrm{Au}_{N}-\mathrm{G} 1$ than to $\mathrm{Au}_{N}-\mathrm{G} 2$.

Table 1 Comparison of BE (in kcal mol ${ }^{-1}$ ) for the complexes of different-sized gold clusters obtained with the PW92, PBE, and DC-PBE functionals

\begin{tabular}{lllll}
\hline & PW92 & PBE & DC-PBE & DC-PBE (COSMO) \\
\hline $\mathrm{Au}_{13}-\mathrm{G} 1$ & 44.9 & 27.7 & 31.3 & 33.5 \\
$\mathrm{Au}_{55}-\mathrm{G} 1$ & 35.3 & 26.5 & 22.0 & 24.1 \\
$\mathrm{Au}_{147}-\mathrm{G} 1$ & 32.0 & 20.8 & 21.8 & 24.3 \\
$\mathrm{Au}_{13}-\mathrm{G} 2$ & 47.2 & 30.3 & 32.4 & 28.2 \\
$\mathrm{Au}_{55}-\mathrm{G} 2$ & 35.8 & 28.9 & 25.0 & 20.3 \\
$\mathrm{Au}_{147}-\mathrm{G} 2$ & 24.9 & 16.3 & 18.1 & 13.7
\end{tabular}

This may be attributed to the fact that the polar $\mathrm{N}-\mathrm{H}$ bond is exposed to the solvent part in $\mathrm{Au}_{N}-\mathrm{G} 1$, while this is not the case in $\mathrm{Au}_{N}-\mathrm{G} 2$. Moreover, the dipole moment is much larger in $\mathrm{Au}_{N}-\mathrm{G} 1$ than in $\mathrm{Au}_{N}-\mathrm{G} 2$, as summarized in Table 2. Thus, $\mathrm{Au}_{N}-\mathrm{G} 1$ is more polar than $\mathrm{Au}_{N}-\mathrm{G} 2$ and gains a larger solvation stabilization in water.

3.1.2 Under-coordination-induced surface quantum trapping. Fig. 2 compares the shell-resolved Mulliken charges of gold atoms within the clusters. Distinct intracluster charge separation is observed for the gold NPs in the complexes, which is expected from our previous considerations. ${ }^{9}$ Negative charges tend to shift toward the outermost shells, and consequently positive charges are left behind in the inner shells of the gold NPs and the complexes. The shifting charges are identified as valence electrons. This observation is consistent with that reported by Staykov et al. ${ }^{62}$ and can be understood in terms of the under-coordinationinduced quantum trapping, ${ }^{6,9}$ as illustrated in Fig. 1c.

Table 2 compares the gross Mulliken charges of bare neutral gold NPs, $\mathrm{Au}_{N}-\mathrm{G} 1$, and $\mathrm{Au}_{N}-\mathrm{G} 2$. The surface negative charge $\left(Q_{1}\right)$ increases upon complexation, as a result of electron donation from $\mathrm{G}$ to $\mathrm{Au}$ NPs. The gross charge of a gold NP $\left(Q_{\mathrm{NP}}\right)$ is larger in $\mathrm{Au}_{N}-\mathrm{G} 1$ than in $\mathrm{Au}_{N}-\mathrm{G} 2$, indicating that the electron donation is more significant in $\mathrm{Au}_{N}-\mathrm{G} 1$. This also relates to the back-donation of a gold NP as discussed in Section 3.2. Because the complex is neutral, the negative charge of $\mathrm{Au}$ NPs $\left(Q_{\mathrm{NP}}\right)$ and positive charge of $\mathrm{G}\left(Q_{\mathrm{G}}\right)$ form a dipole $\left(Q_{\mathrm{G}}=-Q_{\mathrm{NP}}\right)$, with their centers located at

$$
\mathbf{R}_{\mathrm{NP} / \mathrm{G}}=\frac{\sum_{i}^{\mathrm{NP} / \mathrm{G}} q_{i} \mathbf{r}_{i}}{Q_{\mathrm{NP} / \mathrm{G}}}
$$

where $q_{i}$ and $\mathbf{r}_{i}$ correspond to the Mulliken charge and coordinates at the $i$ th site, respectively. Then, the classical dipole moment $(\boldsymbol{\mu})$ can be calculated as:

$$
\begin{aligned}
\boldsymbol{\mu} & =\left|Q_{\mathrm{NP}}\right| \cdot \mathbf{R}_{\mathrm{NP}-\mathrm{G}}=\left|Q_{\mathrm{NP}}\right| \cdot\left(\frac{\sum_{i}^{\mathrm{G}} q_{i} \mathbf{r}_{i}}{Q_{\mathrm{G}}}-\frac{\sum_{i}^{\mathrm{NP}} q_{i} \mathbf{r}_{i}}{Q_{\mathrm{NP}}}\right) \\
& =\sum_{i}^{\text {complex }} q_{i} \mathbf{r}_{i}
\end{aligned}
$$

Thus, the magnitude of $\boldsymbol{\mu}$ is calculated as the product of the transferred charge value $\left|Q_{\mathrm{NP}}\right|$ and the charge-center distance $\left|\mathbf{R}_{\mathrm{NP}-\mathrm{G}}\right|\left(=\mathrm{R}_{\mathrm{NP}-\mathrm{G}}\right)$. This appears to be different from the conventional method for the calculation of the classical dipole

\begin{tabular}{|c|c|c|c|c|c|c|c|c|c|}
\hline & $\mathrm{Au}_{13}$ & $\mathrm{Au}_{13}-\mathrm{G} 1$ & $\mathrm{Au}_{13}-\mathrm{G} 2$ & $\mathrm{Au}_{55}$ & $\mathrm{Au}_{55}-\mathrm{G} 1$ & $\mathrm{Au}_{55}-\mathrm{G} 2$ & $\mathrm{Au}_{147}$ & $\mathrm{Au}_{147}-\mathrm{G} 1$ & $\mathrm{Au}_{147}-\mathrm{G} 2$ \\
\hline$Q_{1}$ & -0.15 & -0.61 & -0.48 & -0.75 & -1.31 & -1.12 & -1.21 & -1.88 & -1.70 \\
\hline$Q_{\mathrm{NP}}$ & 0.00 & -0.45 & -0.33 & 0.00 & -0.43 & -0.31 & 0.00 & -0.43 & -0.31 \\
\hline$R_{\mathrm{NP}-\mathrm{G}}$ & N/A & 9.06 & 2.21 & N/A & 7.84 & 4.72 & N/A & 7.40 & 3.00 \\
\hline$\mu$ & 0.00 & 4.07 & 0.73 & 0.00 & 3.36 & 1.46 & 0.00 & 3.15 & 0.94 \\
\hline
\end{tabular}
moment, i.e. $\mu=\left|\sum_{i}^{\text {complex }} q_{i} \mathbf{r}_{i}\right|$; however, eqn (6) shows that the

Table 2 Comparison of gross charges of the first shell $\left(Q_{1}\right)$ and the entire NP $\left(Q_{N P}\right) . R_{N P-G}$ (in $\AA$ ) is the distance between the charge centers of Au NPs and G. The classical dipole moments $(\mu)$ of the complexes are calculated by the product of $\left|Q_{\mathrm{NP}}\right|$ and $R_{\mathrm{NP}-\mathrm{G}}$ 
two methods are equivalent and give the same value of $\mu$. As can be seen in Table 2, $\mu$ of a bare Au NP is zero because of the high symmetry of the NP structure. Moreover, $\mu$ for $\mathrm{Au}_{N}-\mathrm{G} 1$ is much larger than that for $\mathrm{Au}_{N}-\mathrm{G} 2$. This is attributable to the larger degree of charge transfer in $\mathrm{Au}_{N}-\mathrm{G} 1$ and partly to its larger $\mathrm{R}_{\mathrm{NP}-\mathrm{G}}$. The center of $Q_{\mathrm{G}}$ is near $\mathrm{N} 2$ of $\mathrm{G}$, which makes $\mathrm{R}_{\mathrm{NP}-\mathrm{G}}$ in $\mathrm{Au}_{N}-\mathrm{G} 1$ much larger than in $\mathrm{Au}_{N}-\mathrm{G} 2$.

3.1.3 Shell-resolved valence charge polarization. Fig. 3a compares the density of states (DOS) for the gold NPs with different sizes. The main peak of the DOS for $\mathrm{Au}_{13}$ shifts by about 0.05 Hartree more toward $E_{\mathrm{F}}$ than does that for $\mathrm{Au}_{147}$, indicating that the degree of valence charge polarization decreases in the order $\mathrm{Au}_{13}>\mathrm{Au}_{55}>\mathrm{Au}_{147}$. Furthermore, the normalized localized DOS (LDOS) spectra in Fig. 3b show that the valence charges at the first atomic shell shift up toward $E_{\mathrm{F}}$ more significantly than those of the inner atoms (black arrow), as a result of polarization. Interestingly, the polarized valence electrons of the $\mathrm{Au}(\mathrm{N})$ atomic site contribute most significantly to the formation of a complex, whereas the valence electrons of other sites are left almost intact. A comparison of Fig. $3 \mathrm{~b}$ and c shows that the levels of valence electrons are also relatively high for the edge and face sites of the first atomic shell (higher than -0.1 Hartree, see Fig. 3c), compared with the levels of inner-shell gold atoms (lower than -0.2 Hartree, see Fig. 3b). These indicate that the electrons are well polarized also at the edge and face sites. A relatively high peak is observed for $\mathrm{Au}(\mathrm{N})$ at around -0.05 Hartree, and this peak changes most significantly upon formation of the complex. In addition, the highest LDOS peak for a corner atom is about 1.25 times as high as those for the edge and face atoms (see dashed-dotted lines in Fig. 3c). The greater amount of polarized valence changes at $\mathrm{Au}(\mathrm{N})$ should contribute efficiently to the $\mathrm{Au}-\mathrm{N}$ bond formation process. Therefore, $\mathrm{G}$ chooses $\mathrm{Au}(\mathrm{N})$ over the other sites for the binding. The $\mathrm{Au}_{13}-\mathrm{G}$ and $\mathrm{Au}_{147}-\mathrm{G}$ complexes also exhibit the same trends, as shown in Fig. S2 and S3 in the ESI. $†$

Thus, the higher stability of a small gold NP-G base complex originates from under-coordination-induced surface charge trapping and valence charge polarization. When a $\mathrm{Au}_{N}-\mathrm{G}$ complex is formed, there is an electronic density change at the binding gold, which, together with the electron donation from the $\mathrm{N}_{z}$ lone-pair orbital to gold and the surface charge trapping of the gold NP, assists the binding process.

\subsection{Site effect: $\mathrm{Au}-\mathrm{G}$ back-donation of the polarized charge}

Further analyses of FOs were performed to characterize the local interactions between bonding gold atoms and $\mathrm{G}$ in more detail for two binding patterns, $\mathrm{Au}_{13}-\mathrm{G} 1$ (N5-Au; O-Au) and $\mathrm{Au}_{13}-\mathrm{G} 2(\mathrm{~N} 5-\mathrm{Au} ; \mathrm{H} \cdots \mathrm{Au})$.

3.2.1 $\mathbf{A u}_{13}-\mathbf{G 1}$ (N5-Au; O-Au). Key MOs and FOs for spin-up electrons are shown in Fig. 4. The results for the spin-down electrons were essentially the same, and thus they are summarized in the ESI. $\nmid$ Here, we mean by key FOs those which constitute large portions of MOs. As shown in Fig. $4 \mathrm{a}$ and b, MOs $\psi_{162}{ }^{+}$and $\psi_{163}{ }^{+}$ are formed as a result of $\sigma$-type $\mathrm{Au}-\mathrm{O}$ and $\mathrm{Au}-\mathrm{N}$ orbital interactions between the gold NP and G, respectively. The formation of these interactions gives rise to a fractional $\mathrm{Au}-\mathrm{N}$ bond order $^{48}$ of 0.597
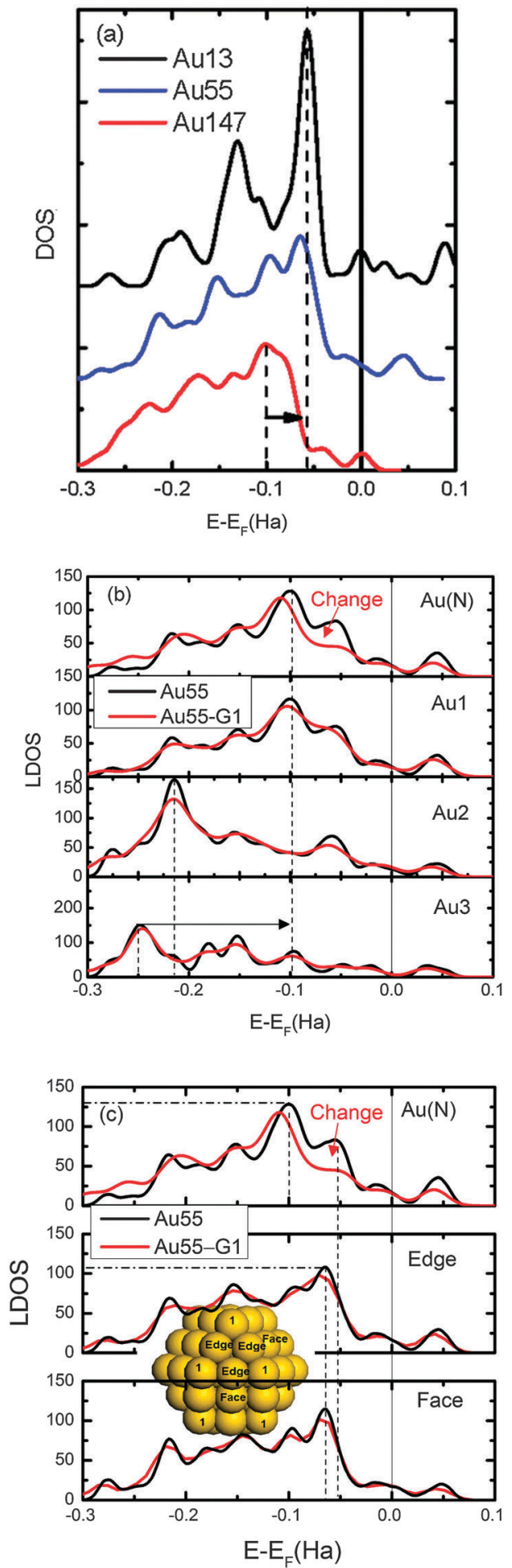

Fig. 3 (a) Comparison of normalized DOS of $A u_{13}, A u_{55}$, and $A u_{147}$. (b) Comparison of normalized LDOS of $\mathrm{Au}_{55}$ and $\mathrm{Au}_{55}-\mathrm{G} 1$ (complex) at the bonding gold atom $(\mathrm{Au}(\mathrm{N}))$ and corner atoms in different shells as labeled in Fig. 1. (c) Comparison of LDOS at three non-equivalent sites (inset) in the first shell. $A u_{N}$ and Au1 in bare particles are placed at the equivalent positions. Black arrows indicate valence charge polarization and red arrows show the significant change in LDOS upon complex formation.

and a $\mathrm{Au}-\mathrm{O}$ bond order of 0.247 , as shown in Fig. 1 . These MOs are largely accounted for by the occupied $\mathrm{p}_{z}$-type $g_{37}$ and $g_{38}$ 


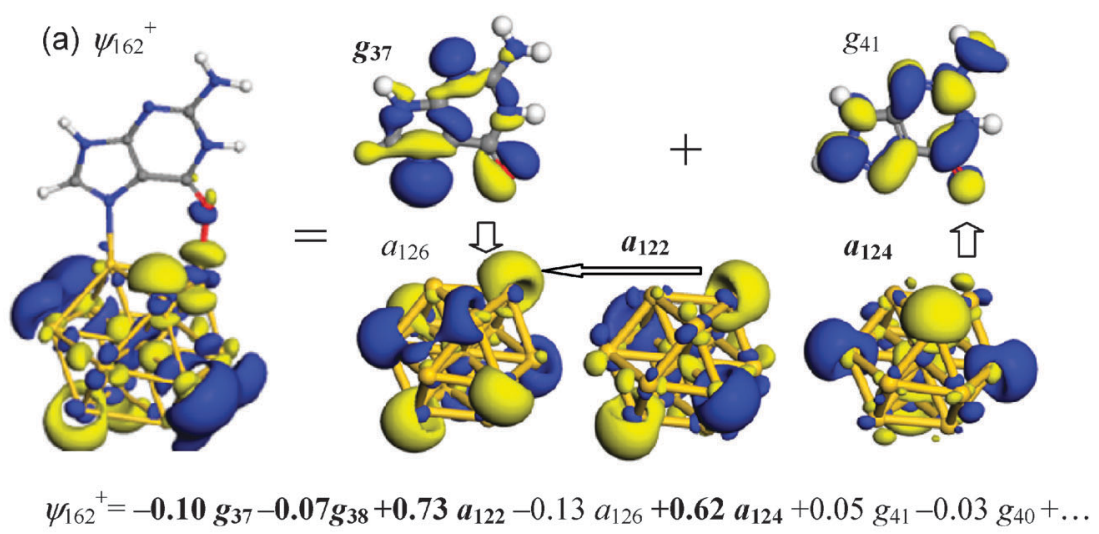

(b) $\psi_{163}{ }^{+}(\mathrm{HOMO})$
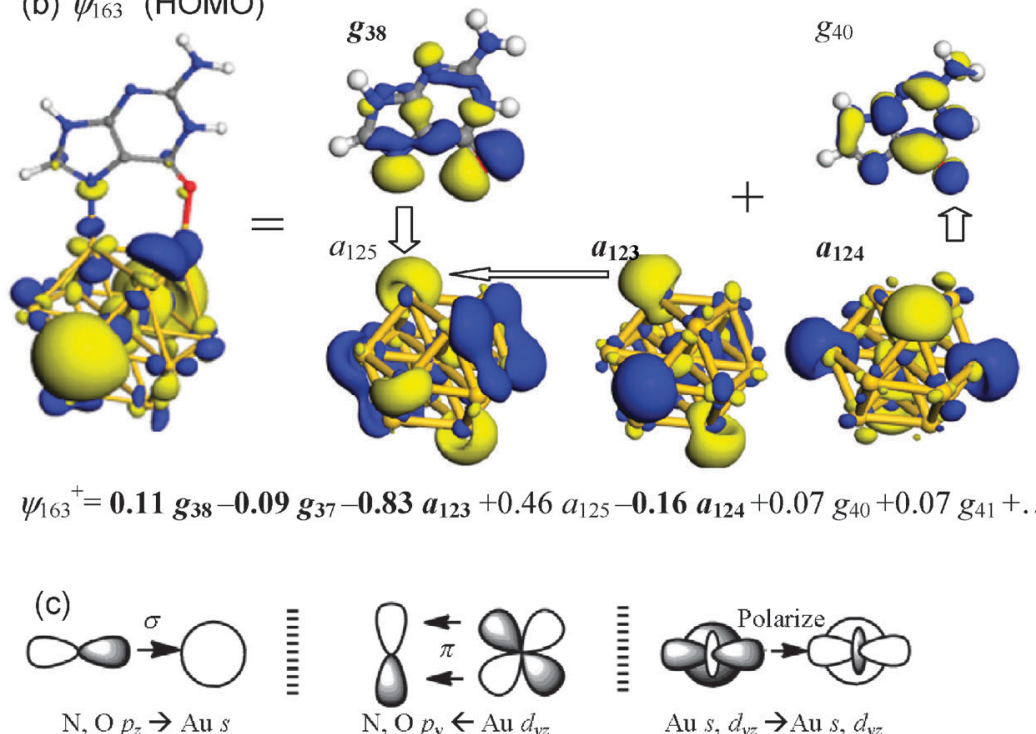

$-\mathbf{0 . 8 3} a_{123}+0.46 a_{125}-\mathbf{0 . 1 6} a_{124}+0.07 g_{40}+0.07 g_{41}+\ldots$
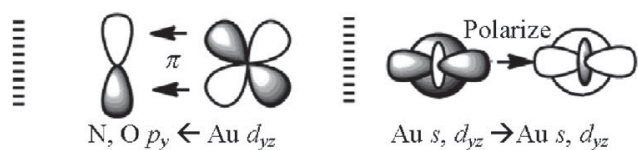

Fig. 4 Summary of key MOs and FOs of $\mathrm{Au}_{13}-\mathrm{G} 1$. (a) $\psi_{162}{ }^{+}$, which contains $\mathrm{Au}-\mathrm{O}$ interaction. (b) $\psi_{163}{ }^{+}(\mathrm{HOMO})$, which contains Au-N interaction. Dominant FO expansion coefficients of the MO are shown underneath each orbital diagram, where occupied FOs are highlighted in boldface. (c) Schematic drawings of key orbital interactions.

FOs and the unoccupied Au s-type ${a_{125}}^{+}, a_{126}{ }^{+}$and ${a_{127}}^{+}$FOs. There is also $\pi$ back-donation from the occupied Au d $\mathrm{d}_{y z} a_{124}{ }^{+}$ orbital to the unoccupied $\mathrm{p}_{y}$-type $g_{40}$ and $g_{41}$ orbitals. Contributions from other FOs are very small.

Key orbital interactions between $\mathrm{Au}_{13}$ and $\mathrm{G}$ in $\mathrm{Au}_{13}-\mathrm{G} 1$ and expansion coefficients of FOs are summarized in Fig. 4c. The following insights are derived: (i) electrons are donated from the lone-pair orbitals of $\mathrm{N}$ and $\mathrm{O}$ to the unoccupied $\mathrm{Au}$ 6s and $6 \mathrm{p}_{z}$ orbitals in the binding process; (ii) back-donation also occurs from the $\mathrm{Au} \mathrm{d}_{y z}$ to the $\mathrm{N}$ and $\mathrm{O} \mathrm{p}_{y}$ orbitals through $\pi$ orbital interaction; and, (iii) there is charge polarization from the occupied to unoccupied FOs within the Au cluster, enhancing the $\mathrm{Au}-\mathrm{N}$ and $\mathrm{Au}-\mathrm{O} \sigma$-type interactions.

The nature of $\mathrm{Au}-\mathrm{G}$ bonding can be understood either from expansion coefficients or from gross populations. Table 3 summarizes the changes in gross populations of frontier FOs upon $\mathrm{Au}_{13}-\mathrm{G} 1$ formation. Complete data are summarized in the ESI. $\dagger$ A negative value means a loss of electrons from the original state. The populations of orbitals around the HOMO and the
Table 3 Changes in electron population of frontier FOs upon formation of $\mathrm{Au}_{13}-\mathrm{G} 1$. Notable changes are highlighted in boldface

\begin{tabular}{|c|c|c|c|}
\hline \multicolumn{2}{|l|}{$\mathrm{Au}_{13}$} & \multicolumn{2}{|l|}{$\underline{G}$} \\
\hline FO & Change & FO & Change \\
\hline$a_{119}{ }^{+}$ & -0.012 & $g_{36}$ & -0.006 \\
\hline$a_{120}{ }^{+}$ & -0.008 & $g_{37}$ & -0.105 \\
\hline$a_{121}{ }^{+}$ & -0.001 & $g_{38}$ & -0.070 \\
\hline$a_{122}{ }^{+}$ & -0.021 & $g_{39}{ }^{a}$ & -0.006 \\
\hline$a_{123}{ }^{+}$ & -0.180 & $g_{40}^{b}$ & 0.019 \\
\hline$a_{124}{ }^{+a}$ & -0.015 & $g_{41}$ & 0.018 \\
\hline$a_{125}+b$ & 0.270 & $g_{42}$ & 0.002 \\
\hline$a_{126}{ }^{+}$ & 0.062 & $g_{43}$ & 0.012 \\
\hline$a_{127}^{+}$ & 0.050 & $g_{44}$ & 0.002 \\
\hline$a_{128}{ }^{+}$ & 0.004 & $g_{45}$ & 0.001 \\
\hline
\end{tabular}

lowest-unoccupied MO (LUMO) are seen to undergo significant changes upon the formation of $\mathrm{Au}_{13}-\mathrm{G} 1$. Consistent with the insights gained from the FO expansion coefficients, the gold NP not only accepts electrons from guanine $2 \mathrm{p}_{z}$-type FOs $g_{37}$ and 
$g_{38}$ into its unoccupied 6s-type ${a_{125}}^{+},{a_{126}}^{+}$and $\mathrm{d}_{z^{2}}$-type $a_{127}{ }^{+}$, but it also donates electrons from its occupied $\mathrm{d}_{y z}$-type FOs $a_{119}{ }^{+}$and $a_{124}{ }^{+}$to guanine $\mathrm{p}_{y}$-type $g_{40}, g_{41}$ and $g_{43}$. There is a significant charge loss in occupied Au $6 \mathrm{~s}$ and $5 \mathrm{~d}_{z^{2}}$ FO $a_{123}{ }^{+}(-0.18)$, whereas there is a gain in unoccupied $\mathrm{Au} 6 \mathrm{~s}$ and $5 \mathrm{~d}_{z^{2}}$ FO $a_{125}{ }^{+}(0.27)$, indicating that valence charges are substantially polarized from occupied orbitals to unoccupied orbitals.

3.2.2 $\mathrm{Au}_{13}-\mathrm{G} 2$ (N5-Au; $\left.\mathbf{H} \cdots \mathbf{A u}\right)$. Key FOs of $\mathrm{Au}_{13}-\mathrm{G} 2$ are shown in Fig. 5. The HOMO $\left(\psi_{163}{ }^{+}\right)$is formed as a result of $\sigma$ donation from the $\mathrm{N}$ lone-pair FOs $g_{34}, g_{37}$ and $g_{38}$ to the unoccupied $\mathrm{Au} 6 \mathrm{~s}$ and $6 \mathrm{p}_{z}$-type FOs, as shown in Fig. 5a. The $\mathrm{Au}-\mathrm{N}$ bond order is 0.648 for $\mathrm{Au}_{13}-\mathrm{G} 2$, which is larger than 0.597 for $\mathrm{Au}_{13}-\mathrm{G} 1$. MO $\psi_{161}{ }^{+}$in Fig. 5b involves $\mathrm{Au} \cdots \mathrm{H}-\mathrm{N}$ hydrogen bonding; this orbital is constructed chiefly by the occupied Au 6s-type FOs $\mathrm{a}_{122}{ }^{+}$and $\mathrm{a}_{123}{ }^{+}$with the N-H unoccupied FOs $g_{42}, g_{44}$ and $g_{45}$. The N-H1 and N-H2 bond orders also decrease from $0.927 / 0.918$ in isolated $\mathrm{G}$ to $0.831 / 0.810$ at the $\mathrm{N}-$ $\mathrm{H} \cdots \mathrm{Au}$ sites, indicating that the covalent bond of $\mathrm{N}-\mathrm{H}$ is weakened upon formation of the $\mathrm{H}$ - A Au hydrogen bond.

The interactions between $\mathrm{Au}_{13}$ and guanine in $\mathrm{Au}_{13}-\mathrm{G} 2$ have been summarized in Fig. 5c: (i) electron donation from the $\mathrm{N} 2 \mathrm{p}_{z}$ lone-pair orbital to the unoccupied $\mathrm{Au} 6 \mathrm{~s}$ and $6 \mathrm{p}_{z}$ orbitals results in the formation of a $\mathrm{Au}-\mathrm{N}$ bond; (ii) back-donation is enabled because of the $\mathrm{Au} \cdots \mathrm{H}-\mathrm{N}$ hydrogen bonding; and (iii) the
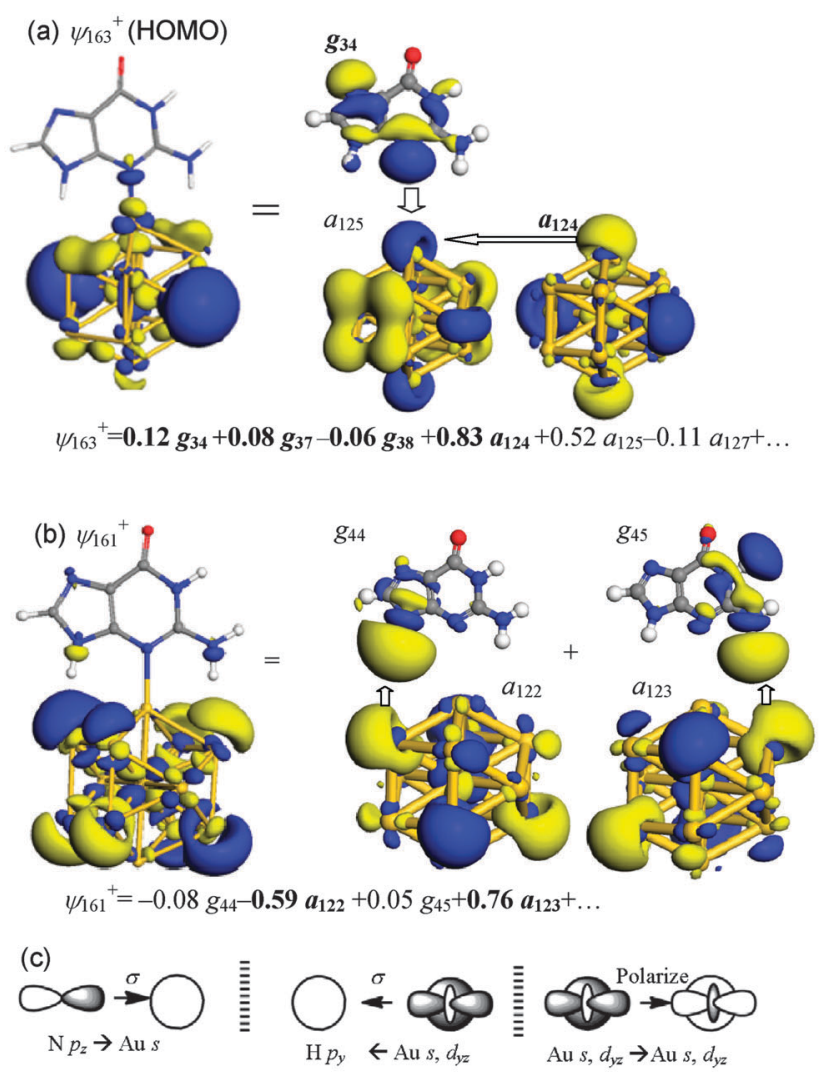

Fig. 5 Summary of key MOs and FOs in $\mathrm{Au}_{13}-\mathrm{G} 2$ of (a) $\psi_{163}{ }^{+}$(HOMO), which contains $\mathrm{Au}-\mathrm{N}$ interaction and (b) $\psi_{161}{ }^{+}$, which contains $\mathrm{Au} \cdots \mathrm{H}-\mathrm{N}$ hydrogen bonds. (c) Schematic drawings of key orbital interactions.
Table 4 Changes in FO population upon formation of $\mathrm{Au}_{13}-\mathrm{G} 2$. Notable changes are highlighted in boldface

\begin{tabular}{|c|c|c|c|}
\hline \multicolumn{2}{|l|}{$\mathrm{Au}_{13}$} & \multicolumn{2}{|l|}{$\mathrm{G}$} \\
\hline FO & Change & FO & Change \\
\hline$a_{119}^{+}$ & -0.016 & $g_{36}$ & -0.001 \\
\hline$a_{120}{ }^{+}$ & -0.003 & $g_{37}$ & -0.049 \\
\hline$a_{121}{ }^{+}$ & -0.001 & $g_{38}$ & -0.025 \\
\hline$a_{122}{ }^{+}$ & -0.020 & $g_{39}{ }^{a}$ & -0.008 \\
\hline$a_{123}{ }^{+}$ & $-\mathbf{0 . 0 3 0}$ & $g_{40} b$ & 0.003 \\
\hline$a_{124}+a$ & -0.200 & $g_{41}$ & 0.005 \\
\hline$a_{125}{ }^{+b}$ & 0.322 & $g_{42}$ & 0.013 \\
\hline$a_{126}{ }^{+}$ & 0.010 & $g_{43}$ & 0.008 \\
\hline$a_{127}^{+}$ & 0.055 & $g_{44}$ & 0.046 \\
\hline$a_{128}{ }^{+}$ & 0.001 & $g_{45}$ & 0.032 \\
\hline
\end{tabular}

occupied $\mathrm{Au} 6 \mathrm{~s}$ and $5 \mathrm{~d}_{z^{2}}$ FOs polarize their charges to the unoccupied $\mathrm{Au}$ FOs and make contributions to the $\mathrm{Au}-\mathrm{N}$ bonding.

Table 4 lists the changes in gross population of each frontier FO upon formation of $\mathrm{Au}_{13}-\mathrm{G} 2$. Consistent with the mechanism obtained from the FO coefficients, besides the donation from the guanine $\mathrm{p}_{z}$-type FOs, $g_{37}$ and $g_{38}$, to the Au 6s-type $\left(a_{125}^{+}\right)$and $5 \mathrm{~d}_{z^{2}}$-type $\left(a_{127}{ }^{+}\right)$FOs, there are charge transfers from gold to N-H unoccupied orbitals $g_{42}, g_{44}$ and $g_{45}$, which can be characterized as H-bond interactions. Moreover, the occupied $a_{124}{ }^{+}$orbital polarizes its charge to the unoccupied $a_{125}{ }^{+}$orbital, as can be seen from their respective population changes of -0.200 and 0.322 .

Comparing the binding models of $\mathrm{Au}_{13}-\mathrm{G} 1$ and $\mathrm{Au}_{13}-\mathrm{G} 2$, one sees that, in both configurations, the guanine $\mathrm{p}_{z}$-type FOs donate electrons to the $\mathrm{Au}$ unoccupied FOs and that the $\mathrm{Au}$ occupied FOs polarize charges to the unoccupied FOs, while back-donation from $\mathrm{Au}$ to $\mathrm{G}$ occurs mainly from $\mathrm{Au} \mathrm{d}_{y z}$-type FOs into the $\pi$-type $\mathrm{p}_{y}$-type FOs of $\mathrm{G}$ in $\mathrm{Au}_{13}-\mathrm{G} 1$. The $\mathrm{N}-\mathrm{H}$ unoccupied FOs accept electrons in the back-donation of $\mathrm{Au}_{13}-\mathrm{G} 2$, to form a $\mathrm{Au} \cdot \mathrm{H}-\mathrm{N}$ hydrogen bond.

3.2.3 Effect of $\mathrm{Au} \cdots \mathrm{H}$ hydrogen bonding on the $\mathrm{N}-\mathrm{H}$ bond order. The significant increase in the number of FOs in larger complexes makes the interpretation of FO-analysis data rather difficult. Therefore, Mayer bond order analyses were performed instead for all complexes to gain insights into the $\mathrm{Au} \cdot \mathrm{H}$ hydrogen bonding. As shown in Table 5, the $\mathrm{N}-\mathrm{H} 1$ and $\mathrm{N}-\mathrm{H} 2$ bond orders remain more or less the same (0.92-0.93) in $\mathrm{Au}_{N}-\mathrm{G} 1$. In contrast, the bond order decreases in a size-dependent manner in $\mathrm{Au}_{N}-\mathrm{G} 2$ as a result of the formation of $\mathrm{Au} \cdot \mathrm{H}$ hydrogen bonds. The values are 0.83 and 0.81 in $\mathrm{Au}_{13}-\mathrm{G} 2,0.883$ and 0.867 in $\mathrm{Au}_{55}-\mathrm{G} 2$, and 0.899 and 0.875 in $\mathrm{Au}_{147}-\mathrm{G} 2$. The smaller $\mathrm{N}-\mathrm{H}$ bond order in a smaller complex reflects the fact that valence charge polarization is larger, as shown in Fig. 3a, which allows the formation of a stronger hydrogen bond.

Table 5 Comparison of Mayer bond orders for the $\mathrm{N}-\mathrm{H} 1$ and $\mathrm{N}-\mathrm{H} 2$ bonds in $\mathrm{Au}_{N}-\mathrm{G} 1$ and $\mathrm{Au}_{N}-\mathrm{G} 2$

\begin{tabular}{lllllll}
\hline & $\mathrm{Au}_{13}-\mathrm{G} 1$ & $\mathrm{Au}_{55}-\mathrm{G} 1$ & $\mathrm{Au}_{147}-\mathrm{G} 1$ & $\mathrm{Au}_{13}-\mathrm{G} 2$ & $\mathrm{Au}_{55}-\mathrm{G} 2$ & $\mathrm{Au}_{147}-\mathrm{G} 2$ \\
\hline $\mathrm{N}-\mathrm{H} 1$ & 0.927 & 0.927 & 0.926 & 0.831 & 0.883 & 0.899 \\
$\mathrm{~N}-\mathrm{H} 2$ & 0.918 & 0.917 & 0.917 & 0.810 & 0.867 & 0.875
\end{tabular}




\section{Conclusions}

Mysteries behind the binding between gold nanoparticles and guanine arise from their complex geometries, electronic structures, bonding types, surface relaxation, symmetry, environments, etc. Regarding the correlation among under-coordination induced surface quantum trapping, valence charge polarization, backdonation from gold and unconventional H-bonds, this theoretical study makes three important suggestions. First, polarization caused by under-coordination effects of gold NPs results in the activation of valence electrons. Second, the binding mode between a gold NP and guanine is not described as a pure $\mathrm{N}-\mathrm{Au}$ donor-acceptor interaction; rather, it also contains $\pi$ - or $\sigma$-back-donations from polarized $\mathrm{Au}$ valence charges. Third, $\mathrm{Au} \cdots \mathrm{H}-\mathrm{N}$ bonding exists that features orbital interaction between a gold $\sigma$ FO and a $\mathrm{N}-\mathrm{H} \sigma^{*}$ FO. The under-coordination-induced surface charge polarization also affects the favorable binding mode.

The under-coordination effect at the surface of gold NPs leads to core-shell charge separations. The surface valence charges are polarized toward $E_{\mathrm{F}}$ and thus contribute more significantly to the back-donation to a base. It is verified that the smallest $\mathrm{Au}_{13} \mathrm{NP}$ undergoes a dramatic valence charge polarization and can form a stable complex with guanine. Furthermore, the FO analysis shows that, besides the electron donation from $\mathrm{N}$ to $\mathrm{Au}$, there is backdonation in the formation of $\mathrm{Au}-\mathrm{G}$ complexes. While $\mathrm{Au}_{13}$ and $\mathrm{Au}_{55}$ prefer the $\mathrm{G} 2$ binding mode, $\mathrm{Au}_{147}$ prefers $\mathrm{G} 1$ because the valence charge polarization and the back-donation ability are weak. In $\mathrm{Au}_{13}-\mathrm{G} 1$, back-donation is through the formation of a $\pi$ bond between $\mathrm{Au} \mathrm{d}_{y z}$ and $\mathrm{N} \mathrm{p}$. In contrast, in $\mathrm{Au}_{13}-\mathrm{G} 2$, backdonation occurs mainly through two $\mathrm{N}-\mathrm{H} \cdots$ Au hydrogen bonds, from the $\mathrm{Au} 5 \mathrm{~d}_{z^{2}}$ and $6 \mathrm{~s}$ orbitals to the $\mathrm{N}-\mathrm{H} \sigma^{*}$ orbital. This unconventional $\mathrm{H}$ bonding leads to intensification of the $\mathrm{Au}$-base interaction, especially in smaller complexes.

\section{Acknowledgements}

This work was supported by a Nanyang Assistant Professorship. We thank the High Performance Computing Centre at Nanyang Technological University for computer resources.

\section{References}

1 N. L. Rosi, D. A. Giljohann, C. S. Thaxton, A. K. R. Lytton-Jean, M. S. Han and C. A. Mirkin, Science, 2006, 312(5776), 1027-1030.

2 P. Ghosh, G. Han, M. De, C. K. Kim and V. M. Rotello, Adv. Drug Delivery Rev., 2008, 60(11), 1307-1315.

3 A. M. Alkilany and C. J. Murphy, J. Nanopart. Res., 2010, 12(7), 2313-2333.

4 D. A. Schafer, J. Gelles, M. P. Sheetz and R. Landick, Nature, 1991, 352(6334), 444-448.

5 Q. Jiang, L. H. Liang and D. S. Zhao, J. Phys. Chem. B, 2001, 105(27), 6275-6277.

6 C. Q. Sun, Phys. Rev. B: Condens. Matter Mater. Phys., 2004, 69(4), 045105.

7 T. Fujita, P. Guan, K. McKenna, X. Lang, A. Hirata, L. Zhang, T. Tokunaga, S. Arai, Y. Yamamoto, N. Tanaka, Y. Ishikawa,
N. Asao, Y. Yamamoto, J. Erlebacher and M. Chen, Nat. Mater., 2012, 11(9), 775-780.

8 A. S. K. Hashmi, Science, 2012, 338(6113), 1434.

9 X. Zhang, J.-l. Kuo, M. Gu, X. Fan, P. Bai, Q.-G. Song and C. Q. Sun, Nanoscale, 2010, 2(3), 412-417.

10 W. J. Huang, R. Sun, J. Tao, L. D. Menard, R. G. Nuzzo and J. M. Zuo, Nat. Mater., 2008, 7(4), 308-313.

11 W. H. Qi, B. Y. Huang and M. P. Wang, J. Comput. Theor. Nanosci., 2009, 6, 635-639.

12 P. Donnadieu, S. Lazar, G. A. Botton, I. Pignot-Paintrand, M. Reynolds and S. Perez, Appl. Phys. Lett., 2009, 94(26), 263116.

13 J. N. Crain and D. T. Pierce, Science, 2005, 307(5710), 703-706. 14 K. Schouteden, E. Lijnen, D. A. Muzychenko, A. Ceulemans, L. F. Chibotaru, P. Lievens and C. V. Haesendonck, Nanotechnology, 2009, 20(39), 395401.

15 B. Wang, K. D. Wang, W. Lu, J. L. Yang and J. G. Hou, Phys. Rev. B: Condens. Matter Mater. Phys., 2004, 70(20), 205411.

16 Y. Yamamoto, T. Miura, M. Suzuki, N. Kawamura, H. Miyagawa, T. Nakamura, K. Kobayashi, T. Teranishi and H. Hori, Phys. Rev. Lett., 2004, 93(11), 116801.

17 J. Oliver-Meseguer, J. R. Cabrero-Antonino, I. Domínguez, A. Leyva-Pérez and A. Corma, Science, 2012, 338(6113), 1452-1455.

18 D. Benitez, N. D. Shapiro, E. Tkatchouk, Y. Wang, W. A. Goddard and F. D. Toste, Nat. Chem., 2009, 1(6), 482-486.

19 S. V. Aradhya, M. Frei, M. S. Hybertsen and L. Venkataraman, Nat. Mater., 2012, 11(10), 872-876.

20 X. Xu, S. H. Kim, X. Zhang, A. Das, H. Hirao and S. H. Hong, Organometallics, 2013, 32, 164-171.

21 P. Pyykkö, Science, 2000, 290(5489), 64-65.

22 R. Vargas and A. Martinez, Phys. Chem. Chem. Phys., 2011, 13(28), 12775-12784.

23 H.-J. Xie, Q.-F. Lei and W.-J. Fang, J. Mol. Model., 2012, 18(2), 645-652.

24 G. Shafai, S. Hong, M. Bertino and T. S. Rahman, J. Phys. Chem. C, 2009, 113(28), 12072-12078.

25 G.-J. Cao, H.-G. Xu, R.-Z. Li and W. Zheng, J. Chem. Phys., 2012, 136(1), 014305-014308.

26 E. S. Kryachko, J. Mol. Struct., 2008, 880(1-3), 23-30.

27 A. Kumar, P. C. Mishra and S. Suhai, J. Phys. Chem. A, 2006, 110(24), 7719-7727.

28 N. K. Jena, K. R. S. Chandrakumar and S. K. Ghosh, J. Phys. Chem. C, 2012, 116(32), 17063-17069.

29 A. Martínez, J. Phys. Chem. C, 2010, 114(49), 21240-21246.

30 M. K. Shukla, M. Dubey, E. Zakar and J. Leszczynski, J. Phys. Chem. C, 2009, 113(10), 3960-3966.

31 E. S. Kryachko and F. Remacle, Nano Lett., 2005, 5(4), 735-739.

32 A. Martínez, J. Phys. Chem. A, 2009, 113(6), 1134-1140.

33 L. Zhang, T. Ren, X. Yang, L. Zhou and X. Li, Int. J. Quantum Chem., 2013, 113(19), 2234-2242.

34 L. Zhang, T. Ren, L. Zhou, J. Tian and X. Li, Comput. Theor. Chem., 2013, 1019(0), 1-10.

35 M. Brust, M. Walker, D. Bethell, D. J. Schiffrin and R. Whyman, J. Chem. Soc., Chem. Commun., 1994, 801-802. 
36 A. C. Templeton, W. P. Wuelfing and R. W. Murray, Acc. Chem. Res., 1999, 33(1), 27-36.

37 R. Cerf, The Wulff Crystal in Ising and Percolation Models, Springer, 2006.

38 C. L. Cleveland, U. Landman, T. G. Schaaff, M. N. Shafigullin, P. W. Stephens and R. L. Whetten, Phys. Rev. Lett., 1997, 79(10), 1873.

39 K. P. McKenna, Phys. Chem. Chem. Phys., 2009, 11, 4097.

40 Y. Pei, Y. Gao, N. Shao and C. Z. Xiao, J. Am. Chem. Soc., 2009, 131(38), 13619-13621.

41 P. D. Jadzinsky, G. Calero, C. J. Ackerson, D. A. Bushnell and R. D. Kornberg, Science, 2007, 318(5849), 430-433.

42 H. Qian, W. T. Eckenhoff, Y. Zhu, T. Pintauer and R. Jin, J. Am. Chem. Soc., 2010, 132(24), 8280-8281.

43 M. Zhu, C. M. Aikens, F. J. Hollander, G. C. Schatz and R. Jin, J. Am. Chem. Soc., 2008, 130(18), 5883-5885.

44 B. Corain, G. Schmid and N. Toshima, Metal Nanoclusters in Catalysis and Materials Science: The Issue of Size, Elsevier B.V., 2008.

45 W. Gao, X. F. Chen, J. C. Li and Q. Jiang, J. Phys. Chem. C, 2009, 114(2), 1148-1153.

46 S. J. Bao, Q. L. Bao, C. M. Li, T. P. Chen, C. Q. Sun, Z. L. Dong, Y. Gan and J. Zhang, Small, 2007, 3(7), 1174-1177.

47 C. Q. Sun, Prog. Mater. Sci., 2009, 54, 179.

48 I. Mayer, Int. J. Quantum Chem., 1986, 29, 477-483.

49 B. Delley, J. Chem. Phys., 1990, 92(1), 508-517.
50 B. Delley, Phys. Rev. B: Condens. Matter Mater. Phys., 2002, 66, 155125.

51 J. P. Perdew and Y. Wang, Phys. Rev. B: Condens. Matter Mater. Phys., 1992, 45, 13244.

52 J. P. Perdew, K. Burke and M. Ernzerhof, Phys. Rev. Lett., 1996, 77, 3865-3868.

53 A. Tkatchenko and M. Scheffler, Phys. Rev. Lett., 2009, $102(7), 073005$.

54 I. L. Garzón, K. Michaelian, M. R. Beltrán, A. Posada-Amarillas, P. Ordejón, E. Artacho, D. Sánchez-Portal and J. M. Soler, Phys. Rev. Lett., 1998, 81(8), 1600-1603.

55 A. Mayoral, D. A. Blom, M. M. Mariscal, C. Guiterrez-Wing, J. Aspiazu and M. Jose-Yacaman, Chem. Commun., 2010, 46(46), 8758-8760.

56 Y. Pei, Y. Gao and X. C. Zeng, J. Am. Chem. Soc., 2008, 130(25), 7830-7832.

57 M. R. Beltrán, R. Suárez Raspopov and G. González, Eur. Phys. J. D, 2011, 65(3), 411-420.

58 M. Weinert and J. W. Davenport, Phys. Rev. B: Condens. Matter Mater. Phys., 1992, 45(23), 13709-13712.

59 A. Klamt and G. Schuurmann, J. Chem. Soc., Perkin Trans. 2, 1993, 0(5), 799-805.

60 MATLAB and R2011b, The MathWorks Inc., Natick, MA, 2011. 61 H. Fujimoto, S. Kato, S. Yamabe and K. Fukui, J. Chem. Phys., 1974, 60(2), 572-578.

62 A. Staykov, T. Nishimi, K. Yoshizawa and T. Ishihara, J. Phys. Chem. C, 2009, 116(30), 15992-16000. 